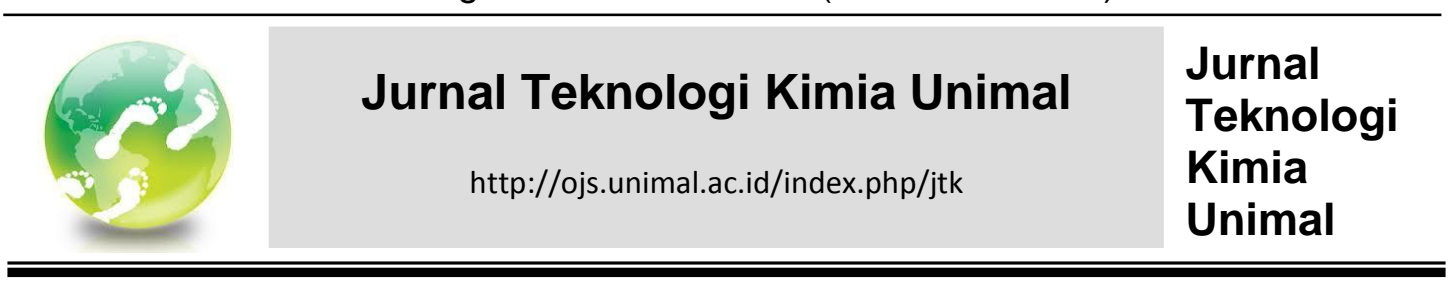

\title{
Pemanfaatan Biji Orok-Orok (Crotalaria juncea) sebagai Bahan Baku Pembuatan Minyak Nabati dengan Metode Ekstraksi Padat-Cair
}

\author{
Tiara Puspa Dwi Seta, Muhammad, Masrullita \\ Jurusan Teknik Kimia Universitas Malikussaleh
}

\begin{abstract}
ABSTRAK
Tanaman orok-orok atau Crotalaria juncea L adalah tanaman leguminosa yang termasuk ke dalam keluarga perdu dan semak Biji orok-orok mengandung $12,6 \%$ minyak dengan 46,8 \% asam linoleat, 4,6 \% asam linolenat, 28,3\% asam oleat dan 20,3\% asam jenuh. Metode yang digunakan adalah metode ekstraksi padat-cair dengan pelarut etanol. Pada penelitian ini dioptimasi menggunakan RSM (Response Surface Methodology). Bahan baku yang digunakan adalah biji orok-orok dan etanol. Biji orok-orok dihaluskan menggunakan blender, kemudian dimasukkan dalam labu leher tiga untuk proses ekstraksi menggunakan pelarut etanol. Ekstraksi dilakukan dengan memvariasikan berat sampel, suhu ekstraksi dan waktu ekstraksi. Dengan variasi berat sampel (70, 80,90 gram), Suhu (55, 65 dan $\left.75^{\circ} \mathrm{C}\right)$, Waktu (3,4 dan 5 jam). Setelah selesai ekstraksi larutan di saring menggunakan kertas saring. Selanjutnya dilakukan pemisahan antara minyak dan pelarut dengan proses destilasi. Pengujian yang dilakukan adalah uji densitas, yield, kadar FFA dan uji komposisi dengan alat GC-MS. Densitas terendah dihasilkan pada Suhu $75^{\circ}$ C, berat sampel 70 dan waktu ekstraksi 4 jam sebesar $0,788 \mathrm{~g} / \mathrm{ml}$. Yield tertinggi dihasilkan pada suhu $65^{\circ} \mathrm{C}$, berat sampel $90 \mathrm{gr}$ dan waktu ekstraksi 3 jam sebesar 19,943\%. Kadar FFA terendah dihasilkan pada suhu $65^{\circ} \mathrm{C}$, berat sampel 90 dan waktu 5 jam. RSM memberikan hasil optimasi terbaik pada suhu $75^{\circ} \mathrm{C}$, berat sampel 89,64 gram dan waktu ekstraksu 3 jam dengan yield 19,943, densitas 0,89 gr/ml dan kadar FFA 1,2674\%. Dari hasil uji GC-MS diketahui bahwa minyak biji orok-orok mengandung methyl ester of undecanoic acid, 2-methylpentanoic acid, myristic acid methyl ester, methyl linolelaidate, 2-cyclopentylacetohydrazide dan 2-methylpentanoic acid.
\end{abstract}

Kata Kunci : biji orok-orok, ekstraksi, densitas, yield, kadar FFA

\section{Utilization of Crotalaria juncea Seeds a Raw Material for Making Vegetable Oil using Solid-Liquid Extraction Methods}

Crotalaria juncea $\mathrm{L}$ is a legume plant that belongs to the shrub and bush family. The orangutum seeds contain $12.6 \%$ oil with $46.8 \%$ linoleic acid, $4.6 \%$ linolenic acid, $28.3 \%$ oleic acid and $20.3 \%$ saturated acid. The method used is the solidliquid extraction method with ethanol solvent. In this study, it was optimized using RSM (Response Surface Methodology). The raw materials used are 
Crotalaria juncea seeds and ethanol. The seeds are blended using a blender, then put in a three-neck flask for the extraction process using ethanol solvent. Extraction is done by varying the sample weight, extraction temperature and extraction time. With variations in sample weight (70, 80.90 grams), temperature $\left(55,65\right.$ and $\left.75^{\circ} \mathrm{C}\right)$, time $(3,4$ and 5 hours $)$. After that the extraction the solution is filtered using Distilatian. Then the separation between oil and solvent is carried out by the distillation process. Tests carried out were density, yield, FFA content and composition test using GC-MS. The lowest density was produced at Temperature $75^{\circ} \mathrm{C}$, sample weight 70 and extraction time of 4 hours was $0.788 \mathrm{~g} /$ $\mathrm{ml}$. The highest yield was produced at $65^{\circ} \mathrm{C}, 90$ gram sample weight and 3 hours extraction time of $19.943 \%$. The lowest FFA levels were produced at $65^{\circ} \mathrm{C}, 90$ sample weights and 5 hours. RSM provides the best optimization results at a temperature of $75^{\circ} \mathrm{C}, 89.64$ gram sample weight and extraction time of 3 hours with a yield of 19.943 , density $0.89 \mathrm{gr} / \mathrm{ml}$ and FFA content of $1.2674 \%$. From the GC-MS test results it is known that the seed oil of the snore-containing methyl ester of undecanoic acid, 2-methylpentanoic acid, myristic acid methyl ester, methyl linolelaidate, 2-cyclopentylacetohydrazide and 2-methylpentanoic acid.

Key Word: crotalaria juncea, extraction, density, yield, free fatty acid

\section{Pendahuluan}

Energi fosil adalah energi yang berasal dari pembusukan makhluk hidup selama berjuta-juta tahun. Tumbuhan berkayu berubah menjadi batu bara, sedangkan hewan berubah menjadi minyak bumi. Energi fosil digunakan untuk beberapa kebutuhan di dunia. Batu bara digunakan sebagai bahan bakar pada mesin industry, sedangkan minyak bumi digunakan sebagai bahan bakar kendaraan bermotor. Indonesia merupakan salah satu penghasil minyak bumi, jumlah energy fosil melimpah, banyak ditemukan batu bara di beberapa daerah. Namun untuk menjadi energi fosil dibutuhkan waktu berjuta-juta tahun, dan dapat dihabiskan hanya dalam beberapa hari.

Krisis energi di Indonesia disebabkan oleh peningkatan konsumsi minyak bumi dalam kehidupan sehari-hari. Salah satu jenis minyak bumi adalah solar sebagai bahan bakar mesin diesel. Langkah yang dapat dilakukan untuk mengurangi konsumsi solar adalah menggunakan biodiesel sebagai bahan bakar 
mesin diesel. Biodiesel adalah bahan bakar alternatif untuk mesin diesel yang dihasilkan dari reaksi transesterifikasi antara minyak nabati atau minyak hewani yang mengandung trigliserida dengan alkohol seperti metanol dan etanol. Reaksi transesterifikasi ini memerlukan katalis basa kuat seperti natrium hidroksida atau kalium hidroksida sehingga menghasilkan senyawa kimia baru yang disebut metil ester.

Ide penggunaan minyak nabati sebagai pengganti bahan bakar diesel didemonstrasikan pertama kalinya oleh Rudolph Diesel ( \pm tahun 1900). Penelitian di bidang ini terus berkembang dengan memanfaatkan beragam lemak nabati dan hewani untuk mendapatkan bahan bakar hayati (biofuel) dan dapat diperbaharui (renewable). Perkembangan ini mencapai puncaknya di pertengahan tahun 80-an dengan ditemukannya alkil ester asam lemak yang memiliki karakteristik hampir sama dengan minyak diesel fosil yang dikenal dengan biodiesel. Pembuatan biodiesel dari minyak nabati dilakukan dengan mengkonversi trigliserida (komponen utama minyak nabati) menjadi metil ester asam lemak, dengan memanfaatkan katalis pada proses metanolisis/esterifikasi. Beberapa katalis telah digunakan secara komersial dalam memproduksi biodiesel. Selain itu, juga diupayakan katalis katalis dari sisa produksi alam seperti, janjang sawit, abu sekam padi dan sebagainya.

Salah satu tumbuhan yang mengandung minyak nabati adalah biji orokorok (Crotalaria Juncea). Crotalaria juncea $L$ termasuk tanaman leguminosa yang mampu mengikat $\mathrm{N}$ secara bebas dari udara, dapat menghasilkan biomassa dengan cepat, tinggi kandungan air dan $\mathrm{N}$ dan memiliki perakaran yang dalam sehingga dapat memompa unsur hara ke permukaan tanah. Orok-orok memiliki potensi yang besar untuk dikembangkan menjadi bahan baku pembuatan biodiesel. Biji orok-orok mengandung 12,6\% minyak dengan 46,8\% asam linoleat, 4,6 \% asam linolenat,28,3 \% asam oleat dan 20,3\% asam jenuh (Asmiyenti,2017). Biodiesel dari biji orok orok dapat dibuat dengan cara 
mengekstrak minyak dari biji orok-orok dengan metode ekstraksi padat-cair dengan memvariasikan suhu, berat, sampel dan waktu ekstraksi.

\section{Metode Penelitian}

Penelitian dilaksanakan di Laboratorium Teknik Kimia, Universitas Malikussaleh selama satu bulan. Bahan yang digunakan berupa biji orok-orok dan etanol. Adapun alat penelitiannya adalah blender, labu leher tiga, seperangkat alat ekstraksi, seperangkat alat distilasi, piknometer, pipet volume, corong, neraca analitis, kertas saring, dan aluminium Foil.

Penelitian diawali dengan pemilihan bahan baku, selanjutnya ditunggu beberapa hari untuk mengurangi kadar air. Biji yang sudah kering diperkecil ukuran menggunakan blender. Biji yang sudah halus di ekstraksi dengan jumlah pelarut $250 \mathrm{ml}$. proses ekstraksi dilakukan dengan variasi waktu 3, 4, 5 jam dan variasi suhu 55,65 dan $75^{\circ} \mathrm{C}$. Hasil ekstraksi dimasukkan kedalam labu destilasi, solven dipisahka dengan cara evaporasi dengan suhu operasi $70^{\circ} \mathrm{C}$.

\section{Hasil dan Pembahasan}

Penelitian ini didesain menggunakan Response Surface Methodology (RSM) dengan Software Design Expert 7.0.0. Hasil penelitian yang akan dianalisa ialah densitas, yield dan kadar FFA. Berdasarkan hasil penelitian yang diperoleh, maka data pengamatan proses ekstraksi minyak biji orok-orok dapat dilihat pada Tabel 1.

\subsection{Persamaan Regresi Pada Analisa Densitas}

Berdasarkan dari hasil analisa densitas minyak pada proses ekstraksi didapat persamaan:

$$
\begin{aligned}
\mathrm{Y} 1= & -0,40978+0,00175(\mathrm{~A})+0,0272(\mathrm{~B})+0,0415(\mathrm{C})-0,0000275(\mathrm{AB})-0,00005 \\
& (\mathrm{AC})+0,0065(\mathrm{BC})+0,00004125\left(\mathrm{~A}^{2}\right)-0,00021875\left(\mathrm{~B}^{2}\right)-0,008625
\end{aligned}
$$

Dimana: A = Berat Sampel,

$$
\mathrm{B}=\text { Suhu Ekstraksi, }
$$




$$
\begin{aligned}
& \mathrm{C}=\text { Waktu Ekstraksi, } \\
& \mathrm{Y}_{1}=\text { Densitas Minyak Biji Orok-orok }
\end{aligned}
$$

Dari hasil analisa response surface methodology (RSM) dengan menggunakan design expert didapatkan persamaan regresi model orde II dengan model quadratic.

Keakuratan model tersebut dapat diketahui dari harga $\mathrm{R}$-squared $\left(\mathrm{R}^{2}\right)$ yaitu 0.9974 berdasarkan nilai tersebut dapat disimpulkan bahwa densitas yang diperkirakan dengan model mendekati nilai yang diperoleh dari hasil penelitian. Nilai $\mathrm{R}^{2}>0.5859$ artinya model dapat diterima. Hal ini menunjukkan bahwa model orde II sangat signifikan dan dapat mewakili hubungan antara variabel respon dengan variabel independen. Untuk membuktikan kelayakan model tersebut perlu dilakukan analisa varian dan uji kelayakan model.

\section{a. Validasi Model Statistik}

Validasi hasil prediksi terhadap data hasil eksperimen dapat dilihat pada Tabel 2.

Tabel 1 Data Hasil Penelitian Menggunakan Software Design Expert

\begin{tabular}{|c|c|c|c|c|c|c|c|}
\hline Run & Block & \begin{tabular}{|l|} 
Factor 1 \\
A:Berat sampe \\
gram
\end{tabular} & \begin{tabular}{|l|} 
Factor 2 \\
B:suhu ekstrah \\
Celcius
\end{tabular} & \begin{tabular}{|l|} 
Factor 3 \\
C:waktu ekstra \\
Menit
\end{tabular} & $\begin{array}{c}\text { Response 1 } \\
\text { Densitas } \\
\mathrm{gr} / \mathrm{ml}\end{array}$ & $\begin{array}{c}\begin{array}{c}\text { Response } 2 \\
\text { yield } \\
\text { gr }\end{array} \\
\end{array}$ & $\begin{array}{c}\text { Response } 3 \\
\text { Kadar FFA } \\
\% \\
\end{array}$ \\
\hline 1 & Block 1 & 80.00 & 75.00 & 5.00 & 0.86 & 9.944 & 1.4 \\
\hline 2 & Block 1 & 80.00 & 75.00 & 3.00 & 0.82 & 12.886 & 1.56844 \\
\hline 3 & Block 1 & 80.00 & 65.00 & 4.00 & 0.878 & 10.95 & 1.96 \\
\hline 4 & Block 1 & 80.00 & 55.00 & 5.00 & 0.862 & 12.05 & 1.79156 \\
\hline 5 & Block 1 & 70.00 & 55.00 & 4.00 & 0.801 & 8.713 & 1.54 \\
\hline 6 & Block 1 & 70.00 & 75.00 & 4.00 & 0.788 & 7.925 & 1.4 \\
\hline 7 & Block 1 & 90.00 & 55.00 & 4.00 & 0.938 & 17.143 & 1.71063 \\
\hline 8 & Block 1 & 80.00 & 65.00 & 4.00 & 0.878 & 10.95 & 1.96 \\
\hline 9 & Block 1 & 80.00 & 55.00 & 3.00 & 0.848 & 12.189 & 1.96 \\
\hline 10 & Block 1 & 80.00 & 65.00 & 4.00 & 0.878 & 10.95 & 1.96 \\
\hline 11 & Block 1 & 90.00 & 65.00 & 3.00 & 0.928 & 19.943 & 1.73578 \\
\hline 12 & Block 1 & 90.00 & 75.00 & 4.00 & 0.914 & 17.143 & 1.4 \\
\hline 13 & Block 1 & 70.00 & 65.00 & 5.00 & 0.82 & 8.633 & 1.28844 \\
\hline 14 & Block 1 & 80.00 & 65.00 & 4.00 & 0.878 & 10.95 & 1.96 \\
\hline 15 & Block 1 & 70.00 & 65.00 & 3.00 & 0.803 & 9.375 & 1.93047 \\
\hline 16 & Block 1 & 90.00 & 65.00 & 5.00 & 0.943 & 14.444 & 1.00844 \\
\hline 17 & Block 1 & 80.00 & 65.00 & 4.00 & 0.878 & 10.95 & 1.96 \\
\hline
\end{tabular}
t.6.0.8. 
Tiara Puspa Dewi Seta, dkk / Jurnal Teknologi Kimia Unimal 8 : 2 (November 2019) 47 - 52

Tabel 2 Validasi Hasil Prediksi Model Pengaruh suhu, waktu dan berat sampel terhadap densitas

\begin{tabular}{|r|r|r|r|r|r|r|}
\hline \multirow{2}{*}{ Run } & \multicolumn{3}{|c|}{ Variabel Bebas } & \multicolumn{3}{c|}{ Densitas } \\
\cline { 2 - 7 } & $\begin{array}{r}\text { Suhu } \\
\left({ }^{\circ} \mathrm{C}\right)\end{array}$ & $\begin{array}{c}\text { Massa biji } \\
\text { (gr) }\end{array}$ & $\begin{array}{c}\text { Waktu } \\
\text { (Jam) }\end{array}$ & Aktual & Prediksi & $\begin{array}{c}\text { Persen } \\
\text { Kesalahan }\end{array}$ \\
\hline 1 & 75 & 80 & 5 & 0.86 & 0.856 & 0.004 \\
\hline 2 & 75 & 80 & 3 & 0.82 & 0.822 & 0.002 \\
\hline 3 & 65 & 80 & 4 & 0.88 & 0.878 & 0 \\
\hline 4 & 55 & 80 & 5 & 0.86 & 0.86 & 0.002 \\
\hline 5 & 55 & 70 & 4 & 0.8 & 0.802 & 0.001 \\
\hline 6 & 75 & 70 & 4 & 0.79 & 0.791 & 0.003 \\
\hline 7 & 55 & 90 & 4 & 0.94 & 0.935 & 0.003 \\
\hline 8 & 65 & 80 & 4 & 0.88 & 0.878 & 0 \\
\hline 9 & 55 & 80 & 3 & 0.85 & 0.852 & 0.004 \\
\hline 10 & 65 & 80 & 4 & 0.88 & 0.878 & 0 \\
\hline 11 & 65 & 90 & 3 & 0.93 & 0.927 & 0.001 \\
\hline 12 & 75 & 90 & 4 & 0.91 & 0.913 & 0.001 \\
\hline 13 & 65 & 70 & 5 & 0.82 & 0.821 & 0.001 \\
\hline 14 & 65 & 80 & 4 & 0.88 & 0.878 & 0 \\
\hline 15 & 65 & 70 & 3 & 0.8 & 0.798 & 0.006 \\
\hline 16 & 65 & 90 & 5 & 0.94 & 0.948 & 0.005 \\
\hline 17 & 65 & 80 & 4 & 0.88 & 0.878 & 0 \\
\hline
\end{tabular}

\section{Analisa Varian (ANOVA) Model Orde II}

Analisa varian (ANOVA) untuk model orde II dapat dilihat pada Tabel 3, yaitu untuk mengetahui adanya pengaruh yang signifikan terhadap model pada penelitian pada ANOVA kapasitas penyerapan.

Tabel 3 Data Analisa Varian (ANOVA) Densitas

\begin{tabular}{|c|c|c|c|c|c|c|}
\hline Sumber & \begin{tabular}{|l|} 
Jumlah \\
Kuadrat \\
\end{tabular} & $\mathrm{DF}$ & $\begin{array}{l}\text { Mean } \\
\text { Square }\end{array}$ & F Value & Prob $>F$ & Keterangan \\
\hline Model & 0.03677 & 9 & 0.00409 & 301.83005 & $<0.0001$ & Significant \\
\hline $\mathrm{A}$ & \begin{tabular}{|l|}
0.03264 \\
\end{tabular} & 1 & 0.03264 & 2411.40765 & $<0.0001$ & - \\
\hline B & \begin{tabular}{|l|}
0.00056 \\
\end{tabular} & 1 & 0.00056 & 41.45515 & 0.0004 & - \\
\hline $\mathrm{C}$ & \begin{tabular}{|l|}
0.00092 \\
\end{tabular} & 1 & 0.00092 & 68.30079 & $<0.0001$ & - \\
\hline $\mathrm{AB}$ & \begin{tabular}{|l|}
0.00003 \\
\end{tabular} & 1 & 0.00003 & 2.23483 & 0.1786 & - \\
\hline $\mathrm{AC}$ & \begin{tabular}{|l|}
0.00000 \\
\end{tabular} & 1 & 0.00000 & 0.07388 & 0.7936 & - \\
\hline $\mathrm{BC}$ & 0.00017 & 1 & 0.00017 & 12.48549 & 0.0096 & - \\
\hline $\mathrm{A}^{2}$ & \begin{tabular}{|l|}
0.00007 \\
\end{tabular} & 1 & 0.00007 & 5.29301 & 0.0549 & - \\
\hline $\mathrm{B}^{2}$ & \begin{tabular}{|l|}
0.00201 \\
\end{tabular} & 1 & 0.00201 & 148.85085 & $<0.0001$ & - \\
\hline $\mathrm{C}^{2}$ & \begin{tabular}{|l|}
0.00031 \\
\end{tabular} & 1 & 0.00031 & 23.14054 & 0.0019 & - \\
\hline Residual & \begin{tabular}{|l|}
0.00009 \\
\end{tabular} & 7 & 0.00001 & - & - & - \\
\hline Lack of Fit & \begin{tabular}{|l|}
0.00009 \\
\end{tabular} & 3 & 0.00003 & - & - & - \\
\hline Pure Error & 0 & 4 & 0 & - & - & - \\
\hline Cor Total & 0.03686 & 16 & - & - & - & - \\
\hline
\end{tabular}

Sumber: Softwere Design Expert t7.0.0 
Keterangan :

$$
\begin{aligned}
\text { Mean Square } & =\text { Jumlah Kuadrat Rata-Rata } \\
\text { A } & =\text { Berat sampel } \\
\text { B } & =\text { Suhu Ekstraksi } \\
\text { C } & =\text { Waktu }
\end{aligned}
$$

Nilai probabilitas adalah $\mathrm{P}>\mathrm{F}$

Tabel 4 menunjukkan ANOVA densitas dengan Design Expert 7.0.0 model dapat dinyatakan memiliki pengaruh yang signifikan jika model memiliki nilai probabilitas <0.05. Namun, jika nilai lebih besar dari 0.05 maka model yang ditunjukkan tidak signifikan. Pada Tabel 4.4 menyatakan bahwa persamaan B memiliki nilai probabilitas $<0.05$. Hal ini berarti persamaan B memiliki pengaruh yang signifikan. Sebuah model dapat dikatagorikan sebagai model yang sesuai apabila model tersebut memiliki koefisien korelasi $\mathrm{R}^{2}<1$. Model yang secara statistik dikatagorikan cukup baik bila $\mathrm{R}^{2}$ mendekati nilai tersebut. Model pada penelitian ini menunjukkan nilai $R^{2}$ yaitu 0.9974 . Nilai $R^{2}$ terkoreksi (adj $R$ squared) mengoreksi nilai $\mathrm{R}^{2}$ terhadap temperatur dan konsentrasi serta berat sampel, maka nilai $\mathrm{R}^{2}$ terkoreksi akan lebih kecil dari $\mathrm{R}^{2}$. Nilai $\mathrm{R} 2$ prediksi (pred

\begin{tabular}{|c|c|c|c|c|c|c|}
\hline Source & $\begin{array}{l}\text { Sumof } \\
\text { squares }\end{array}$ & $\mathrm{DF}$ & Mean Square & F Value & Prob $>F$ & Keterangan \\
\hline Mean vs Total & 12.7371 & 1 & 12.73713088 & - & - & - \\
\hline $\begin{array}{l}\text { Linear vs } \\
\text { Mean }\end{array}$ & 0.03413 & 3 & 0.01137525 & 54.002336 & $\begin{array}{l}< \\
0.0001\end{array}$ & - \\
\hline $2 F I$ vs Linear & 0.0002 & 3 & 0.00006675 & 0.2629902 & 0.8505 & - \\
\hline $\begin{array}{l}\text { Quadratic vs } \\
2 F I\end{array}$ & 0.00244 & 3 & 0.000814456 & 60.170883 & $\begin{array}{l}< \\
0.0001\end{array}$ & Suggested \\
\hline $\begin{array}{l}\text { Cubic vs } \\
\text { Quadratic }\end{array}$ & $9.5 \mathrm{E}-05$ & 3 & 0.000031583 & 63660000 & $\begin{array}{l}< \\
0.0001\end{array}$ & Aliased \\
\hline Residual & 0 & 4 & 0 & - & - & - \\
\hline Total & 12.774 & 17 & 0.751411471 & - & - & - \\
\hline \multicolumn{7}{|c|}{ Model Summary Statistics } \\
\hline Source & $\begin{array}{l}\text { Std. } \\
\text { Dev. }\end{array}$ & R-Squared & $\begin{array}{c}\text { Adjusted } \\
\text { R-Squared }\end{array}$ & $\begin{array}{l}\text { Predicted } \\
\text { R-Squared }\end{array}$ & PRESS & Keterangan \\
\hline Linear & 0.01451 & 0.92572 & 0.90857509 & 0.8646569 & 0.00499 & - \\
\hline $2 \mathrm{FI}$ & 0.01593 & 0.93115 & 0.889838995 & 0.7300244 & 0.00995 & - \\
\hline Quadratic & 0.00368 & 0.99743 & 0.994125143 & 0.958876 & 0.00152 & Suggested \\
\hline Cubic & 0 & 1 & 1 & & + & Aliased \\
\hline
\end{tabular}
R-squared ) cukup bersesuaian dengan $\mathrm{R}^{2}$ terkoreksi. Nilai koefisien varian (C.V) mengindikasi bahwa deviasi antara nilai ekperimen dan nilai prediksi rendah.

Tabel 4 Analisa kelayakan densitas 


\section{Uji Kelayakan Model Orde II}

Dalam uji sum of square, suatu model dinyatakan sesuai apabila probabilitas nilai $\mathrm{p}>\mathrm{F}$ adalah lebih kecil dari 0,05 . Pada pengujian $\mathrm{R}^{2}$, tiap-tiap model di lihat dari Adj $\mathrm{R}^{2}$ dan juga Pred $\mathrm{R}^{2}$. Model yang baik adalah model yang memiliki $\mathrm{R}^{2}$ mendekati 1. Adapun nilai Adj $\mathrm{R}^{2}$ adalah 0,6797, Pred $\mathrm{R}^{2}$ 0-1,2419 dan nilai Pred $\mathrm{R}^{2}$ yang diperoleh tidak boleh mendekati nilai dari Adj $\mathrm{R}^{2}$. Bila di lihat pada tabel, model quadratic memenuhi syarat tersebut baik pada Adj $\mathrm{R}^{2}$ maupun pada Pred $\mathrm{R}^{2}$. Sehingga meski nilai dari Adj $\mathrm{R}^{2}$ model kubik lebih tinggi dari pada Adj $\mathrm{R}^{2}$ model quadratic, model kubik tidak dapat dipilih karena nilai Pred $\mathrm{R}^{2}$ memenuhi syarat. Model kuadratik disarankan oleh Softwere Design Expert. Uji kelayakan model orde II ini dapat dilihat pada Tabel 4.

\section{a. Pengaruh Suhu Ekstraksi dan Berat Sampel Terhadap Densitas Minyak Biji orok-orok}

Adapun pengaruh Suhu ekstraksi dan berat sampel terhadap densitas minyak biji orok-orok dapat dilihat pada Gambar 1.

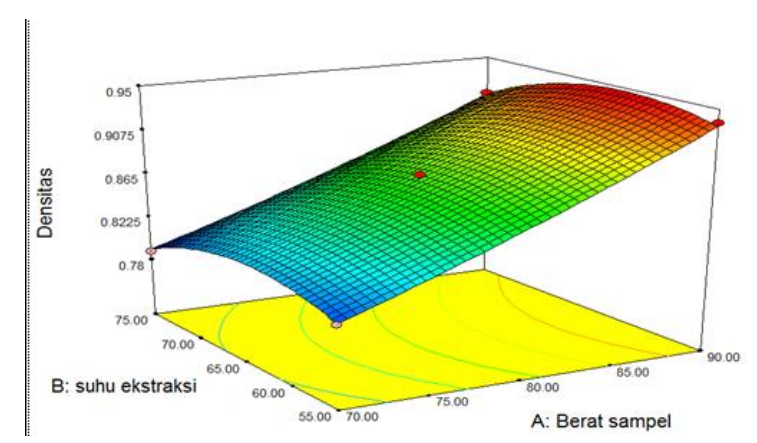

Gambar 1 Pengaruh Suhu ekstraksi dan Berat sampel terhadap Densitas Minyak

Densitas atau berat jenis minyak merupakan kumpulan berat molekul dari berbagai komponen penyusun auatu minyak dalam volume yang telah ditentukan. Harga densitas berkaitan dengan fraksi berat komponen yang terdapat dalam minyak. Berat molekul senyawa berbanding lurus dengan densitas minyak. Semakin berat molekul suatu senyawa maka akan semakin besar densitas minyak 
(Hadrah, 2018). Gambar 4.2 Menunjukkan densitas paling rendah dihasilkan pada suhu $75^{\circ} \mathrm{C}$ dengan berat sampel 70 gr densitas minyak sebesar $0,79 \mathrm{gr} / \mathrm{ml}$, sedangkan densitas minyak tertinggi adalah sebesar 0,943 pada suhu 65 dengan berat sampel $90^{\circ} \mathrm{C}$.

Densitas merupakan perbandingan berat dari suatu volume sampel dengan berat air pada volume yang sama. Perbedaan densitas disebabkan oleh perbedaan berat sampel pada saat penelitian. Semakin banyak sampel yang diberikan maka semakin besar densitas yang didapat. Tidak terdapat interaksi antara suhu ekstraksi dan densitas, karena densitas merupakan sifat fisik dari minyak.

\section{b. Pengaruh Berat Sampel dan Waktu Ekstraksi Terhadap Densitas dari Minyak biji orok-orok}

Adapun pengaruh Berat Sampel dan Waktu Ekstraksi Terhadap Densitas dari Minyak biji orok-orok dapat dilihat pada Gambar 2.

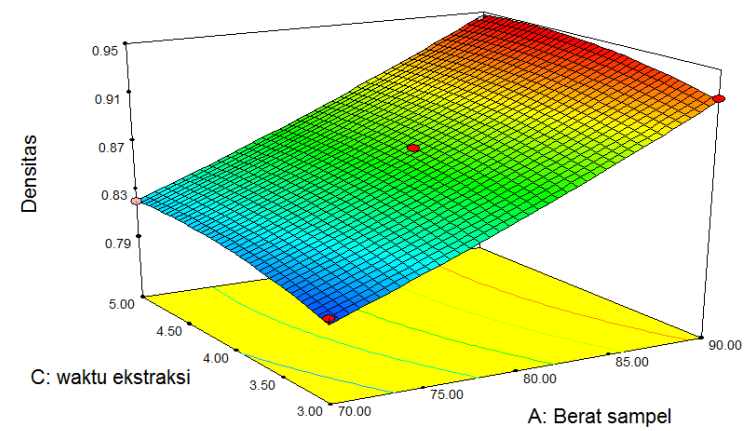

Gambar 2 Waktu ekstraksi dan Berat sampel terhadap densitas minyak biji orokorok

Gambar 2 menunjukkan densitas paling rendah pada waktu 4 jam dengan berat sampel diberikan 70 dan didapat densitas minyak $0,79 \mathrm{gr} / \mathrm{ml}$. Sedangkan densitas tertinggi pada waktu 5 jam dan berat samnpel 90 gram. Hal ini disebabkan karena semakin banyak sampel yang digunakan maka semakin besar komposisi minyak di dalamnya dan semakin tinggi densitas minyak yang didapat. 
Semakin lama waktu ekstraksi maka semakin maksimal minyak di ekstrak pada biji orok-orok.

\section{Kesimpulan}

Berdasarkan hasil pembahasan maka dapat diambil kesimpulan bahwa Densitas terendah dihasilkan pada Suhu $75^{\circ} \mathrm{C}$, berat sampel 70 dan waktu ekstraksi 4 jam sebesar 0,788 . Yield tertinggi dihasilkan pada suhu $65^{\circ} \mathrm{C}$, berat sampel 90 gr dan wajtu ekstraksi 3 jam sebesar 19,943\%. Kadar FFA terendah dihasilkan pada suhu $65^{\circ} \mathrm{C}$, berat sampel 90 dan waktu 5 jam. Hasil metode Response Surface Methodology di dapatkan hasil optimasi terbaik pada suhu $75^{\circ} \mathrm{C}$, berat sampel 89,64, Waktu ekstraksi 3 jam dengan yield sebesar, 19,943, densitas $0,89 \mathrm{gr} / \mathrm{ml}$ dan kadar FFA 1,2674 \%.

\section{Daftar Pustaka}

Ali Ismail Al-Snafi. 2016. The contents and pharmacology of crotalaria juncea. IDSR Journal of Pharmacy. 6(2):1-2

Asmiyenti, D., Djalil, 2017, "Potensi biji orok-orok (Crotalaria Juncea) sebagai kandidat obat insomnia).

Coniwanti, Pamilia.dkk "Proses Ekstraksi Minyak Biji Rosella”. Fakultas Teknik, Jurusan Teknik Kimia, Universitas Sriwijaya.

Dutta. Ratna, U. Sarkar, and A. Mukherjee. 2015 "Extraction of oil from crotalaria juncea seeds in a modified soxhlet apparatus: Physical and chemical characterization of a prospective bio-fuel," Fuel, vol. 116, pp. 794-802.

Dutta. Ratna, U. Sarkar, and A. Mukherjee. 2015 " Soxhlet Extraction of Crotalaria Juncea Oil Using Cylindrical and Annular Packed Beds" vol.6 No. 2

Endah, Purbarani, heny Setyo Purwono, 2007. Pengaruh Jenis Pelarut, Siklus Ekstraksi dan Ukuran Biji Karet Terhadap Yield Minyak Biji Karet. Fakultas Teknik, Jurusan Teknik Kimia, Universitas Sriwijaya, Indralaya.

Guenther, E. (1987).Minyak Atsiri jilid I (Terjemahan). Jakarta : UI Press. Hal. 44-484.

Hadrah., Kasman, M., Sari, F.M., 2018. "Analisis Minyak Jelantah sebagai Bahan Bakar Biodiesel dengan Proses Transesterifikasi”. Universitas Batanghari: Jambi.

Ibrahim, Nasrun. dkk”Pengaruh Waktu Ekstraksi Daun Jeruk Nipis (Citrus aurantifolia) 
Menggunakan Pelarut n-Heksana Terhadap Rendemen Minyak". Jurnal Teknologi Kimia 7:2 (2018): 163-171.

Jayanuddin, dkk, 2014 "Pengaruh Suhu Dan Rasio Pelarut Ekstraksi Terhadap Rendemen Dan Viskositas Natrium Alginat Dari Rumput Laut Cokelat (Sargassum sp)". Fakultas Teknik, Jurusan Teknik Kimia, Universitas Sultan Ageng Tirtayasa.

Ketaren, S. 1986. Pengantar Teknologi Minyak dan Lemak Pangan. Cetakan Pertama. Jakarta : UI-Press. Mangoensoekarjo, S. 2003.

Lenth, RV. 2009. Response Surface Methods in R, Using rsm. Journal of Statistical Software.

McCabe, W, Smith, J.C, and Harriot, P, 1993, "Unit Operation of Chemical Engineering", Mc Graw Hill Book, co, United States of America.

Moeksin, Rosdiana.dkk “ Pengaruh Ukuran Partikel dan Jenis Pelarut Serta Waktu Ekstraksi Terhadap Yield Minyak Piper Retrofractum Vahl”. Fakultas Teknik, Jurusan Teknik Kimia, Universitas Sriwijaya, Indralaya.

Ramadhan, A.E. dan Phaza, H.A., 2010, Pengaruh Konsentrasi Etanol, Suhu dan Jumlah Stage pada Ekstraksi Oleoresin Jahe (Zingiber officinale Rosc.) Secara Batch, Skripsi, Universitas Diponegoro, Semarang.

Reineccius, G., Flavor Chemistri, Di dalam: Hidayat, F. K., Ekstraksi Minyak Atsiri Dari Daun Jeruk Purut (Citrus hystrix DC) pada Skala Pilot-Plant, Sripsi, Jurusan Teknologi Pangan dan Gizi Fakultas Teknologi Pertanian Institut Pertanian Bogor, Bogor (1994).

Sadukhan, Suvra. 2015. Production of Biodiesel from Crotalaria juncea (Sunn -Hemp) Oil Using Catalytic Trans-Esterification: Process Optimisation Using a Factorial and Box-Behnken Design.

Sibuea, Fridaqua Sada Yanitauli. 2015. Ekstraksi Zat Warna Kluwak (Pangium edule Reinw) Menggunakaan Pelarut Etanol dan Aquades menjadi Pewarna Makanan. Program Studi Teknik Kimia DIII. Fakultas Teknik. Universitas Negeri Semarang. 